\title{
LAS EPÍSTOLAS DEL ABISMO DE UGO FOSCOLO: TRES MODALIDADES DEL SUICIDIO DISCURSIVO EN ULTIME LETTERE DI JACOPO ORTIS
}

Santiago Juan-Navarro*

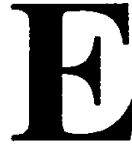

n Ultime lettere di Jacopo Ortis Ugo Foscolo explora los motivos y técnicas tradicionalmente asociados al género epistolar. Esta reflexión se materializa en tres niveles discursivos: amoroso (búsqueda de la plenitud personal a través de un objeto de deseo), político (lucha por la unidad e identidad nacionales) y literario (creación de una nueva forma de expresión y de una nueva audiencia). En cada uno de estos tres niveles las contradicciones del protagonista, Jacopo Ortis, le sitúan en un callejón sin salida del que sólo puede escapar mediante su autodestrucción. La intención del presente ensayo es estudiar cada uno de estos niveles en relación con la estructura epistolar de la novela de Foscolo.

La fragmentación del material narrativo y la dispersión de sus voces y destinatarios son reflejo de la escisión espiritual característica del hombre romántico y de la desintegración política de Italia a comienzos del siglo XIX. Por otro lado, la tensión resultante del enfrentamiento entre postulados estéticos excluyentes (neoclasicismo y romanticismo, artificiosidad y espontaneidad, escritura y oralidad) tiende, en última instancia, a problematizar el acto mismo de escribir y, por lo tanto, la base misma del género epistolar.

* Florida Internacional University 
JUAN-NAVARRO, S. Las epistolas del abismo...

Ultime lettere es considerada por algunos críticos como la primera novela propiamente italiana. ${ }^{1}$ En la redacción de lo que los críticos consideran el germen de su novela (el "Proto Ortis"), Foscolo se valió de los modelos existentes en el siglo XVIII. La mayoría de ellos estaban construídos siguiendo las pautas del modo epistolar. Especial influencia tuvieron en Foscolo Pamela de Richardson (sobre la que escribiría un ensayo) y La Nouvelle Héloise de Rousseau. En su forma original la obra de Foscolo tenía como escenario Venecia antes del tratado de Campoformio, por el cual la República de Venecia pasó a manos de Austria. Bajo el título inicial de Laura, lettere Foscolo escribió un romance sentimental inspirado en la tradición amorosa de Petrarca. ${ }^{2}$ Fue precisamente el mencionado tratado y la situación del autor como proscrito y exiliado, lo que le llevó a darle a la novela una orientación política. Al mismo ticmpo, la lectura del recientemente aparecido Werther de Goethe tuvo un impacto decisivo en el autor italiano. ${ }^{3}$ El resultado de estas confluencias fue Ultime lettere de Jacopo Ortis, donde la corrupción política de Italia y los infortunios amorosos llevan al protagonista al suicidio.

La llamada edición londinense de la novela (publicada realmente en Zúrich) aparece dividida en dos partes que incluyen un total de aproximadamente setenta cartas y abarcan un período de cerca de tres años (desde el 11 de octubre de 1797 hasta el 20 de marzo de 1799). ${ }^{4}$ La extensión y el contenido de las mismas va desde largas confesiones amorosas y digresiones políticas a breves

1 Veáse en este sentido el comentario de Radcliff-Umstead en su introducción a la traducción inglesa de las cartas (1970a, p. 10).

2 Al parecer, esta primera aventura epistolar de Foscolo no fue más allá de un simple experimento, un borrador que el autor se vio obligado a presentar a sus editores a pesar de que él mismo lo considerara incompleto: "Questo libro non è interamente compiuto, ma l'autore è costretto a dargli l'ultima mano quando anche egli non volesse" ("Piano di Studi," en Opere, VI, p. 6; citado por Nicoletti 1978, p. 49n12).

3 La influencia de Goethe se convirtió desde el principio en un lugar común de la crítica foscoliana. El propio autor no ignoraba esta posibilidad y dejó constancia de las diferencias entre su obra y la de Goethe en el apartado VI de su "Notizia bibliografica" (1970, p. 504-527). Aunque la mayor parte de los ensayos sobre Foscolo tratan este tema, son de especial interés las monografías de Graff (1895), Marpillero (1900), Zumbini (1905), Dapelo (1953), Massano (1965), y Manacorda (1973), así como el estudio de Radcliff-Umstead (1970b, p. 54-55).

4 El cómputo se hace difícil ya que en ocasiones las cartas quedan interrumpidas para interpolar fragmentos de otras o los comentarios del supuesto editor. La confusión es aún mayor al existir tres versiones distintas de Ultime lettere. Las citas de la novela que recoge el presente trabajo provienen del cuarto volumen de la Edizione Nazionale delle Opere di Ugo Foscolo (1970). En esta edición de sus obras completas se reproducen íntegramente las tres versiones existentes: Bolonia (1798), Milán (1802) y Zúrich (1816). La que los críticos llaman edición londinense es, en realidad, una reimpresión de la versión de Zúrich que Murray publicó en la capital inglesa un año después. 
notas o misivas escritas apresuradamente. En ellas Jacopo, un joven burgués envueito en las luchas políticas de la Italia del momento, confiesa a su amigo Lorenzo su amor apasionado y su descontento ante la situación del país. El encuentro con la heroína se produce cuando Jacopo huye de Venecia por razones políticas. Camino del exilio traba amistad con un tal Signor T*** y sus dos hijas (Isabella y Teresa). Al comprender que se está enamorando de Teresa y que su relación es imposible (la joven está prometida al noble Odoardo), Jacopo emprende un exilio no ya sólo político, sino también espiritual, al que sólo pondrá fin mediante el suicidio.

A esta trama, aparentemente sencilla y evocadora de buena parte de los clisés de la novela sentimental, se contrapone una complejidad narrativa que va más allá del básico circuito emisor-receptor propio de la novela epistolar. La voz narrativa predominente al comienzo de la novela es, sin duda, la de Jacopo. Lorenzo, por su parte, se limita a cumplir su papel como editor de las cartas que a través de emisarios recibe del protagonista. Conforme el discurso de este último va haciéndose cada vez más fragmentario, como consecuencia de su derrumbamiento emocional, la figura de Lorenzo va adquiriendo un mayor peso específico en la novela. ${ }^{5}$ En muchos sentidos podríamos llegar a decir que se convierte en el protagonista, o al menos, en el orquestador de esa sinfonía caótica en vías de desintegración que es el pensamiento de Jacopo. ${ }^{6}$ Lorenzo organiza cronológicamente cartas y fragmentos que recibe, no ya mediante un mensajero, sino a través del correo. En muchas ocasiones se producen espacios de indeterminación entre unas cartas y fragmentos, que Lorenzo debe resolver mediante sus comentarios en primera y tercera persona.

Aún cuando la novela adquiera ocasionalmente el modo narrativo más común (la tercera persona), Lorenzo, se cuida de insistir desde el principio en la veracidad de lo narrado (afirma haber presenciado los hechos, o haberlos

5 El carácter fragmentario de la narrativa foscoliana ha sido interpretado de modo muy diverso por los críticos. Lo que para unos es defecto estilístico, para otros es una gran innovación de la técnica narrativa. De cualquier modo, parece razonable atribuir, como hace Verna, tal fragmentarismo a la estructura propia del discurso epistolar. Esta última es la postura de Verna que en su ensayo sobre Foscolo ("Dal frammento all'unità: la struttura epistolare delle Ultime lettere di Jacopo Ortis," en Pugliese 1989, p. 31-39), pretende "illustrare come certi aspetti del ben noto frammentismo della scrittura foscoliana costituiscano un tutt'uno non solo con le istanze ideologiche e morali del Nostro, ma anche, e non meno significativo, con la struttura stessa dell'opera che andiamo analizzando" (1989, p. 31).

6 Esta idea es la desarrolla Verna en el ensayo arriba mencionado: "Tale sara lo spessore di questa sua obliqua presenza testuale che essa finirà col conferire a Lorenzo lo stafus di un vero personaggio romanzesco..." (1989, p. 35). 
recogido fielmente de testigos oculares). ${ }^{7}$ Las cartas del propio Lorenzo y de Teresa son ocasionalmente reproducidas en Ultime lettere, en el primer caso como citas inscritas en cartas de Jacopo, en el segundo, como resultado de la labor compiladora de Lorenzo. Una voz menos clara, pero presente en toda obra literaria, es la del autor implícito, entendido este como "the governing consciousness of the work as a whole, the source of the norms embodied in the work" (Rimmon-Kenan, 1983, p. 86). Esta fuerza organizadora que permanece en la sombra articularía las dos voces principales de la novela (Jacopo y Lorenzo) con todos aquellos elementos narrativos que sirven de vehículo al autor para expresar su visión del mundo. Se trata, en suma, de la voz del propio texto expresándose a sí mismo.

La variada gama de voces narrativas que despliega el texto de Foscolo se corresponde con una multiplicación de la figura del destinatario. Aunque Lorenzo es el receptor básico del grueso de cartas recogidas por él mismo, Teresa, el Signor $\mathrm{T}^{* * *}$, la madre de Jacopo, el país y sus héroes, la naturaleza, y hasta Dios mismo, se revelan como encarnaciones del "tu" o del "voi" a los que se dirige el narrador. A todo ello se añade la figura de lo que Wolfgang Iser llama "the implied reader" y que es correlativa al citado concepto del autor implícito: "the reader whom the text creates for itself and amounts to 'a network or response-inviting structures,' which predispose us to read in cetain ways" (Selden, 1986, p. 112).

En los tres apartados siguientes comentaré la articulación (y en ocasiones desarticulación) de estos emisores y destinatarios en relación con los tres niveles discursivos mencionados y los motivos principales del género epistolar.

7 Al igual que el Werther de Goethe, Ultime lettere se abre con una advertencia al lector escrita por el destinatario y supuesto editor de las cartas (Wilhelm, en el primer caso, Lorenzo, en el segundo). Tanto Wilhelm como Lorenzo insisten su tarea objetiva de recopiladores de hechos verídicos y solicitan la simpatía del lector en relación con las desventuras de sus protagonistas. 


\section{"Je est un autre:" amor, amistad, muerte, y el diálogo con el Otro}

Fratelli, a un tempo stesso, Amore e Morte

Leopardi

La carta como "forma de relación individual y social" (Guillén, 1985, p. 169) ofrece el marco perfecto para el dialogismo que propone Bajtin en su teoría de la novela. El género epistolar, asimismo, dramatiza el carácter comunicativo que el crítico ruso ve como uno de los elementos clave en la formación de las formas novelísticas. De especial relevancia para el tema que estamos tratando es su concepto de la "Otredad." Aunque la antropología filosófica de Bajtin es sumamente compleja y, en ocasiones, contradictoria (Todorov, 1984, p. 100), me limitaré a subrayar algunas ideas básicas en relación con el concepto de la Otredad y su relación con la creación literaria.

Para Bajtin es imposible concebir nuestra propia identidad al margen de la presencia del Otro. Somos conscientes de nuestro ser físico y psicológico a través de la percepción y la conciencia de los demás. Esto lleva a Bajtin a establecer la absoluta necesidad estética que el ser humano manifiesta por su semejante. La estructura epistolar alegorizaría, por tanto, ese "intenso encuentro" entre el Yo y el Otro que Bajtin considera imprescindible para alcanzar el autoconocimiento. Desde este punto de vista, ser significa comunicar, y para que la comunicación tenga efecto, aunque resulte obvio decirlo, es imprescindible la presencia de un destinatario: "The very being of man (both internal and external) is the deepest communion. To be means to communicate. To be means to be for another, and through the other, for oneself" [énfasis del autor] (Bajtin, 1984, p. 287).

La carta actúa como vehículo en este acto comunicativo: conector entre dos puntos distantes, puente que se tiende entre un emisor (yo-presente) y un receptor (el otro-ausente). Como sugiere Altman, el autor epistolar puede enfatizar tanto la distancia como el puente, el medio (1982, p. 13). En Ultime lettere veremos como Jacopo, la voz narrativa principal, recurre alternativamente a ambas posibilidades. La forma misma de la carta parece apropiada para el argumento amoroso por su énfasis característico en los motivos de la separación y el encuentro. ${ }^{8}$ El héroe romántico de Fóscolo es consciente de esta

8 La carta funciona tanto en Foscolo como en Goethe como vehículo estructurador de la 
JUAN-NAVARRO, S. Las epístolas del abismo...

interrelación entre estos dos motivos, de la forma en que el propio medio de comunicación refleja tanto la presencia como la ausencia del destinatario.

En la obra de Fóscolo, el discurso amoroso aparece entrelazado con el de la amistad. Las cartas, salvo unas pocas excepciones, van todas destinadas al amigo íntimo, al confidente: Lorenzo. ${ }^{9}$ El discurso amoroso de Jacopo se deduce así a través de sus comentarios indirectos. El carácter suicida del mismo queda establecido desde los comienzos de la obra, debido a la imposibilidad de que su amor por Teresa pueda llegar a materializarse en un encuentro definitivo. La negativa de Jacopo a aceptar la inevitable y creciente ausencia de su amada le lleva a una situación insostenible que sólo puede resolverse en el suicidio.

Para poder comprender este proceso autodestructivo, mediante el cual el objeto de deseo se manifiesta como definitivamente inalcanzable y ausente, sería conveniente establecer la estructura general de Ultime lettere.

Las diez primeras cartas funcionan a modo de prefacio, presentando el escenario, los personajes principales y los temas dominantes. En concreto, las cuatro cartas que cubren el período del 11 al 19 de octubre introducen las ideas políticas y morales de Jacopo, explicando sus circunstancias personales. El presagio de la muerte se manifiesta desde un principio mediante un recurrente y obsesivo simbolismo sepulcral. Las tendencias suicidas de Jacopo aparecen ya en la segunda de sus cartas (13 de octubre de 1797). La introducción de veladas alusiones a la trágica historia de Lauretta y a la muerte de su amado Eugenio, sirven para consolidar esta nota ominosa en la que el lector empieza a presentir el triste desenlace de una historia que aún no ha comenzado. ${ }^{10}$ No es

producción de significado que, según Barthes, desata el arrebato amoroso: “Werther n'est pas pervers, il est amoureux: il crée du sens, toujours, partout, de rien, et c'est le sens qui le fait frissonner: il est dans le brasier du sens" (1977, p. 81). En tanto vehículo, la carta actúa por desplazamiento metonímico, como sustituto incompleto del objeto de deseo. El discurso amoroso, el galanteo, se convierte de esta forma en manifestación de un juego erótico indefinido: "le langage est une peau: je frotte mon language contre l'autre...Mon langage temble de désir...(Parler amoureausement, c'est dépenser sans terme, sans crise; c'est pratiquer un rapport sans orgasme. Il existe peut-être une forme littéraire de ce coïtus reservatus: c'est le marivaudage)" (1977, p. 87). Aunque las cartas recogidas en la novela de Foscolo, van en su mayor parte dirigidas a Lorenzo, en ellas recrea Jacopo su relación con Teresa y en especial todos aquellos momentos de contacto físico o espiritual con la amada.

9 Igualmente en Werther el editor, Wilhelm, es el destinatario de la práctica totalidad de las cartas. Sólo dos de ellas van dirigidas a la amada Lotte. Al igual que Lorenzo, Wilhelm irá cubriendo los espacios de ambigüedad que se van creando a medida que las cartas se van haciendo más fragmentarias. El uso de la tercera persona para describir los últimos momentos de los protagonistas es común en las páginas finales de las dos novelas, como lo son también las llamadas de atención al lector.

10 De hecho, el título mismo de la novela de Foscolo, Ultime lettere di Jacopo Ortis, es 
hasta la séptima de las cartas que el lector tiene conocimiento de Teresa como un ser de belleza extraordinaria. Las tres siguientes completan la obertura de la obra recalcando los temas principales (desilusión política, tensión vida/muerte, ostracismo de Jacopo, premonición de su final). Toda la historia de Jacopo aparece resumida en la carta del 20 de noviembre. A partir de aquí el argumento aportará muy poco de nuevo. El propio Foscolo, adelantándose a críticas desfavorables por el carácter estático de la línea argumental, aclaró este punto en su "notizia bibliografica." "Lo que nos interesa por el momento es establecer el progreso de la relación entre Jacopo y Teresa. Es precisamente en esta undécima carta donde Jacopo declara abiertamente su amor por la joven, reconociendo a un mismo tiempo los obstáculos para su pasión. Teresa, por su parte, confiesa su infelicidad ante el futuro enlace matrimonial con Odoardo. Pero el dato más significativo de este pasaje viene dado por el énfasis de Jacopo en el hecho de que sólo Teresa es capaz de compartir con él su apreciación de la naturaleza. En sus descripciones de la belleza inefable del paisaje, Teresa es simultáneamente descrita como un ser rodeado de un aura resplandeciente. Sólo ellos dos pueden llegar a sentir el pulso cósmico del universo.

Hasta aquí lo expresado abiertamente en la superficie del texto: las compulsivas declaraciones de Jacopo en medio de su neurosis amorosa. Cabe preguntarse hasta que punto Teresa es un ser real, o simplemente responde a la proyección del deseo insatisfecho de Jacopo. ${ }^{12}$ Hasta que punto el objeto

ya de por sí indicativo de los motivos de la muerte y el acabamiento que recorren cada una de sus páginas.

11 Foscolo reconoce que "gli avvenimenti tutti che danno principio, progresso e catastrofe all'azione sono cosí scarsi e miseri, che ove si prescinda dagli episodi non basterebbero a dar moto a un cortissimo dramma; e sono tessuti in guisa che il lettore li prevede da sé innanzi tratto; difetto capitale d'arte di cui l'autore o compilatore che sia il quale pubblicò il libro, s'accorse sí poco, che l'eroe disperato della prima lettera è pure, né sí poco, che l'eroe disperato della prima lettera è pure, ne meno, il disperato dell'ultima..." (p. 488; citado en Matteo 1985, p. 241). La obra de Ortis figura como radiología del espíritu de un ser atormentado. En lugar de ofrecer una descripción lógica de las etapas que le conducen al suicidio (como hace Goethe en Werther). Foscolo prefiere detenerse recurrentemente en las contradicciones entre las que se debate Jacopo. La tensión de la novela deriva no ya del argumento, sino de la compleja psicología del personaje.

12 Teresa se convierte en la imaginació de Jacopo en encarnación de lo natural, lo auténtico, la inocencia perdida, en compendio de todos esos principios centralizados que, según Derrida han dominado el pensamiento "logocéntrico" occidental. En su crítica de Lévi-Staruss, Derrida (1967a) estabelece la existencai de un estado de pura inocencia o autenticidad. Estos términos, sublimados por la tradición romántica. se hallan en permanente interacción con su opuesto (natureza/cultura, autenticidad/falsedad, inocencia/pervesión). Privilegiar uno de los elementos del binomio, estabelecer una jerarquía, es perpetrar un acto de violencia contra el carácter ambivalente 
amoroso comparte el sentimento de Angst del protagonista, o sólo responde a un intento de este último por focalizar y transcender su angustia existencial. ${ }^{13}$ Recordemos que, conforme a la noción de la Otredad expuesta anteriormente, únicamente somos capaces de formularnos a nosotros mismos a través del Otro. Teresa y Lorenzo cumplen, aparentemente, esa función que permite a Jacopo llegar a ser él mismo. Pero Teresa cierra desde el principio toda posibilidad de una relación amorosa plena. En el texto su actitud es justificada por el protagonista. Teóricamente debe obedecer la voluntad de su padre, el cual, a su vez, favorece la boda con Odoardo debido a presiones políticas y a razones económicas. El texto encubre, en realidad, un discurso ideológico mucho más poderoso que las anécdotas sentimentales que Foscolo tomó prestadas de Goethe. Como discutiremos en un segundo apartado, Jacopo pertenece a una clase inferior y sus aspiraciones de ascenso en la escala social nada tienen que hacer ante la presencia del noble Odoardo. La sumisión de Teresa a la voluntad paterna no parece acomodarse al imperio de la pasión que domina la sensibilidad romántica.

Lorenzo, su confidente, amigo, y compañero en la lucha política, es por tanto, el único que puede ayudar a Jacopo a realizarse plenamente como ser humano. Y Lorenzo aconseja a Jacopo la huida no sólo de los peligros asociados con la tiranía que gobierna la República de Venecia, sino también del peligro que supone toda relación con la familia del Signor $\mathrm{T}^{* * *}$ (representativa de la aristocracia responsable de la situación del país). Jacopo decide no hacer caso de los consejos de su amigo, para hundirse de lleno en el abismo que se le ofrece en la falsa calma de las Colinas Eugenias. Su decisión de abrazar una causa

del signo. El fracaso amoroso de Jacopo se produce, entre otraz razones, como consecuencia de su incacidad para armonizar los elementos de esta cadena de oposiciones. La tensión resultante le lleva a buscar en la muerte un descanso a su mente atromentada.

13 Los comentarios de Barthes en relación con el personaje de Charlotte en Werther, podrían muy bien aplicarse a la figura de Teresa en Ultime lettere. Como Lotte, Teresa no tiene valor alguna en la novela salvo en relación con el protagonista. Frente a la violenta pasión de Jacopo, la joven idealizada no pasa de ser un personaje pálido y desdibujado, un ser inexistente: "Charlotte est bien fade; c'est le piètre personage d'une mise en scène forte, tourmentée, flamboyante, montée par le sujet Werther; par une décision gracieuse de ce sujet, un objet falor est placé au centre de la scène, et là adoré, encensé, pris à partie, couvert de discours, d'oraisons..." (1977, p. 39). El caráter reflectante del objeto amoroso es, asimismo comentado por Barthes en términos que se correponden con la actitud de Jacopo: "c'est mon désir que je désire" (1977, p. 39). Rafael Argullol considera esta misma concepción narcisista del amor como característica de la sensibilidad romántica: "El enamorado romántico no ama seres reales concretos; ama su propria concepción del amor que él evoca atribuyéndolo a su amante" [énfasis del autor] (1982, p. 286). 
JUAN-NAVARRO, S. Las epístolas del abismo...

perdida de antemano (su amor por Teresa), supone el primero de los suicidios mencionados. ${ }^{14}$

\section{Entre el titanismo y la depresión: el discurso político de Jacopo Ortis}

Names are there, Nature's sacred watchwords, they

Were borne aloft in bright emblazonry;

The nations thronged around, and cried aloud,

As with one voice, Truth, Liberty and Love!

Suddenly fierce confusion fell from heaven

Among them: there was strife, deceit, and fear;

Tyrants rushed in, and did divide the spoil.

Shelley

Como ya hemos apuntado, el discurso amoroso y el propiamente ideológico y político aparecen entrecruzados en la obra de Foscolo. En ocasiones el primero parece subordinado al segundo, lo que conferiría a la obra su originalidad frente al Werther de Goethe. ${ }^{15}$ La primera carta, de hecho, se abre con una invectiva contra Napoleón por haber traicionado a la República de Venecia, dejándola en manos de Austria. El Tratado de Campoformio se convierte pronto en uno de los leit-motifs de la novela. La firma de este tratado representa para toda una generación de italianos la pérdida de la fe en los logros de la Revolución Francesa y el fin de las esperanzas en la unificación del país. ${ }^{16}$

14 Parece significativo el hecho de que Jacopo decida poner fin a su vida clavándose una daga en el corazón. Werther, en cambio, se dispara en la cabeza, "por encima del ojo derecho." El acto de Werther es una reafirmación última del poder del sentimiento frente a la razón. La muerte de Jacopo, sin embargo, se revela como un eslabón más en la larga cadena de autonegaciones que caracteriza su pensamiento. Destruye aquello que más estima ("tutto dipende dal cuore"). Su suicidio deviene destrucción simbólica del deseo, autocastración, ya que como sugiere Barthes, "le caur est l'organe du désir (le cocur se gonfle, défaille, etc., comme le sexe)..." (1977, p. 63).

15 "Foscolo's Ultime lettere di Jacopo Ortis, very much influenced by Werther, adds to the Wertherian suicide motif a perennial Italian concern: despair over the state of the father land" (Altman 1982, p. 148).

16 Hasta que el 18 de febrero de 1861 se reunió en Turín el primer parlamento autónomo italiano, la patria de Foscolo fue objeto de la especulación de las grandes potencias. En 1748 la Guerra de Sucesión Austríaca terminó con el Tratado de Aix-la-Chapelle. De acuerdo con este pacto Austria, Francia y España repartían su hegemonía sobre el territorio italiano. La 
Las primeras líneas de la novela son altamente significativas en este sentido: "Il sacrificio della patria nostra è consumato; tutto è perduto... Poichè ho disperato e della mia patria e di me, aspetto tranquillamente la prigione e la morte" (p. 295). El punto de arranque de la obra tiene como protagonista a un ser desilusionado y en espera de la muerte; exactamente las mismas características de Jacopo hacia el final. La finalidad de esta carta es, como sugiere Radcliff-Umstead, conectar los sucesos de la novela con la situación política: "The novelist wished to present the tragedy of his hero as part of a larger national tragedy" (1970, p. 50). ${ }^{15}$

La indignación que provoca en Jacopo este hecho, se ve acrecentada por la corrupción política del país y el olvido de los héroes nacionales. Este panorama desolador provoca en él un sentimiento de indignación que, sin embargo, nunca llega a cuajar en una actividad política inmediata. Jacopo vocifera, se revuelve y llama a la rebelión. Pero sus gritos son la voz del profeta que clama en el desierto. Su audiencia consiste en una naturaleza indiferente y a menudo hostil, en labriegos que le miran absortos como a un ser estrafalario,

Revolución Francesa tuvo una importante repercusión en Italia, trayendo consigo nuevas condiciones y nuevas ideas. En 1796 Napoleón cruzó los Alpes a la cabeza del ejército francés y ocupó las ciudades más importantes del norte de Italia. Su triunfo fue facilitado por el apoyo recibido por parte de los liberales italianos que veían en Napoleón a un abanderado de los ideales de la revolución burguesa. Entre cstos liberales se encontraba el propio Foscolo, autor de una oda "A Bonaparte, il liberatore." La posterior derrota de los franceses obligó a ceder importantes territorios a Austria, entre ellos, la República de Venecia. La llamada "traición" de Napoleón habría de completarse mediante una interminable seric de invasiones que terminaron con el Congreso de Viena (18141815). Las posiciones de las superpotencias que resultaron de este congreso venían a ser las mismas que las de 1789 o 1795. La edición londinense de las Ultime lettere fue publicada en 1817. Cabe suponer que la intención de Foscolo al dar una orientación más política a su obra era denunciar el hecho de que su patria fuera objeto de tráfico entre las potencias extranjeras. En su carta del 19 de enero de 1797, Jacopo exclama "Venezia era trafficata". Aunque alude directamente al Tratado de Campoformio, Foscolo denuncia una situación que demostró ser recurrente en la historia de Italia hasta su unificación definitiva en la segunda mitad del siglo XIX. Las circunstancias históricas de este período son objeto de meticuloso estudio en los ensayos de Carpanetto y Ricuperati (1987) y Hearder (1987).

17 De hecho, Foscolo cambió la fecha inicial de la carta. En la edición bolonesa figuraba como escrita el 3 de septiembre de 1797. En la versión milanesa lleva por fecha el 2 de octubre, recibiendo definitivamente la del 11 de octubre (edición londinense), fecha en que Bonaparte se allegó a Udine con los austriacos para firmar el tratado. La firma fue completada en Campoformio el 17 del mismo mes. Por medio del tratado, la República de Venecia pasó a formar parte del imperio austriaco. Como señala Altman, "Foscolo's particular concern in the final version of the novel (1802), is the concession of Venice to the Austrians in the Treaty of Campo Formio" (1982, p. 148). 
JUAN-NAVARRO, S. Las epístolas del abismo...

o en Lorenzo, a quien es innecesario convencer, porque comparte las mismas ideas que Jacopo.

Muchas de las digresiones de carácter político en la que se embarca el héroe de Foscolo parten de las reflexiones provocadas por las lecturas de los clásicos y los grandes del Renacimiento italiano (Dante, Petrarca etc.). ${ }^{19}$ En la cuarta carta (18 de octubre de 1797), por ejemplo, un libro de Plutarco que recibe de Lorenzo le sirve a Jacopo para consolarse "de' delitti e delle sciagure dell'umanità volgendo gli occhi ai pochi illustri che, quasi primati dell'umano genere, sovrastano a tanti secoli e a tante genti" (p. 297). Las consecuencias literarias de este contradictorio y constante volver los ojos a los clásicos las discutiré en el último apartado de mi trabajo. Baste de momento señalar el talante aristocrático que se percibe desde el principio en el discurso del protagonista. Esquemáticamente el pensamiento político de Jacopo sigue estas pautas: denuncia de una situación de injusticia, indignación no correspondida (pues sólo unos pocos son capaces de reconocer los males del país), regreso a un pasado prístino y legendario.

Como hemos señalado anteriormente, Jacopo es representante del nuevo orden burgués que pretende desplazar del poder a las viejas y corrompidas estructuras de la nobleza. Pero el pensamiento de Jacopo funciona a menudo según las pautas de la caduca aristocracia que pretende derribar: individualismo, desprecio del vulgo, respeto por las clases y la propiedad privada, etc. Su fascinación por la familia del Signor $\mathrm{T}^{* * *}$ ( familia de origen patricio y, por lo tanto, fuera del alcance de Jacopo), es sintomático de su deseo de promocionarse socialmente. ${ }^{20}$ Lorenzo actúa aquí como la voz de su conciencia política que le

18 De hecho, tanto los comentarios directos del editor como aquellos que se desprende de las cartas del protagonista, nos hacen imaginar a Lorenzo como un ser prudente capaz de una visión política más perspicaz, menos histriónica, pero no por ello, menos revolucionaria.

19 En varios momentos de la narración Jacopo muestra su adoración por los héroes literarios nacionales visitando sus tumbas o aquellos lugares donde vivieron. En la carta del 20 de noviembre de 1797 (la famosa undécima carta), Jacopo describe su peregrinación a Arquà para visitar la que fuera casa de Petrarca. El estado ruinoso en que se encuentra sirve de motivo para una larga digresión sobre el olvido en el que han caído los grandes de la cultura italiana. Poco antes de morir (el 5 de marzo de 1799) Jacopo culmina su periplo sepulcral ante la tumba de Dante con quien se siente profundamente identificado.

20 En el fondo Jacopo anhela, como Werther, ser encasillado, pertenecer, ya sea a un núcleo social mínimo como la familia, la nación o la comunidad humana en general. Pero, al mismo tiempo considera esta integración como un acto de renuncia a su Yo único. Este individualismo feroz. y el sentimiento de rechazo que su personalidad antisocial despierta a su alrededor provocan la soledad del héroe romántico, fuente de euforia pero también de envidia, paranoia y depresión: "Le sujet amoureux voit tous ceux qui l'entourent casés, chacun lui paraissant pourvu d'un petil système pratique et affectif de liaisons contractuelles, dont il se sent exclu; il en éprouve un sentiment ambigu 
JUAN-NAVARRO, S. Las epístolas del abismo...

insta a alejarse de esta familia, esto es, de la aristocracia, para retomar la lucha política en el exilio. Pero Jacopo desoye las advertencias de su amigo. ${ }^{21}$

El magnetismo que ejercen sobre él los delicados miembros de esta familia deviene versión blanda y encubierta de la recurrente atracción del abismo que aturde los instintos de la mente romántica. El Signor $\mathrm{T}^{* * *}$ es claramente un ser tan tiránico como los déspotas responsables de la venta de Venecia a una potencia extranjera. Fuerza a su hija a contraer un matrimonio no deseado con Odoardo, noble y acaudalado. Lo que podría parecer un lugar común en la tradición de la novela sentimental, adquicre una lectura ideológica que no podemos dejar de subrayar. El enlace forzado de Odoardo y Teresa provoca la separación del Signor $\mathrm{T}^{* * *}$ con su mujer, que se opone al matrimonio y es significativamente "exiliada" de las Colinas Eugenias. La acción autoritaria del padre provoca, en última instancia, la infelicidad de Teresa y, en parte, el suicidio de Jacopo. La anónima madre de Teresa y el personaje central comparten su condición de exiliados, pero mientras la primera se enfrenta a la autoridad patriarcal, Jacopo no sólo la acepta, sino que, en ocasiones, la justifica. El Signor $\mathrm{T}^{* * *}$ es, a los ojos de Jacopo, un ser justo y ecuánime que, si toma alguna decisión moralmente cuestionable, lo hace siempre forzado por las circunstancias y en defensa de los intereses familiares. Teresa, en su respeto a la voluntad paterna, muestra, según el protagonista, la virtud de la obediencia y la resignación, una virtud ajena (podríamos decir que antitética) al espíritu romántico y que Jacopo no siempre comparte.

El magnetismo que ejercen sobre él los delicados miembros de esta familia deviene versión blanda y encubierta de la recurrente atracción del abismo que aturde los instintos de la mente romántica. El Signor $\mathrm{T}^{* * *}$ es claramente un ser tan tiránico como los déspotas responsables de la venta de Venecia a una potencia extranjera. Fuerza a su hija a contraer un matrimonio no deseado con Odoardo, noble y acaudalado. Lo que podría parecer un lugar común en la tradición de la novela sentimental, adquiere una lectura ideológica que no podemos dejar de subrayar. El enlace forzado de Odoardo y Teresa provoca la

d'envie et de dérision" (Barthes 1975, p. 55).

21 A diferencia del sujeto "cuerdo", racional, el sujeto amoroso rechaza escoger entre dos alternativas en los momentos de crisis. Su actitud es la de persistir en su irracionalidad, escapar a la elección. En él opera un deseo masoquista de persistir en el sufrimiento, de ceder a la tentación del abismo: "Tel est le discours du sujet "sain": on bien, ou bien. Mais le sujet amoureux répond (c'est ce que fait Werther): j'essaie de me glisser entre les deux membres de l'alternative: c'est-à-dire: je n'ai aucun espoir; mais tout de même... Ou encore: je choisis obstinément de ne pas choisir; je choisis la dérive: je continue" [énfasis del autor] (Barthes 1975, p. 75). 
JUAN-NAVARRO, S. Las epístolas del abismo...

separación del Signor $\mathrm{T}^{* * *}$ con su mujer, que se opone al matrimonio y es significativamente "exiliada" de las Colinas Eugenias. La acción autoritaria del padre provoca, en última instancia, la infelicidad de Teresa y, en parte, el suicidio de Jacopo. La anónima madre de Teresa y el personaje central comparten su condición de exiliados, pero mientras la primera se enfrenta a la autoridad patriarcal, Jacopo no sólo la acepta, sino que, en ocasiones, la justifica. El Signor $\mathrm{T}^{* * *}$ es, a los ojos de Jacopo, un ser justo y ecuánime que, si toma alguna decisión moralmente cuestionable, lo hace siempre forzado por las circunstancias y en defensa de los intereses familiares. Teresa, en su respeto a la voluntad paterna, muestra, según el protagonista, la virtud de la obediencia y la resignación, una virtud ajena (podríamos decir que antitética) al espíritu romántico y que Jacopo no siempre comparte.

La propia estructura de la novela revela, asimismo, el discurso ideológico de Jacopo: imperio y progresiva desintegración del Yo, tensión entre la pasión (romanticismo) y la razón (neoclasicismo), voluntad democrática y tendencias aristocratizantes. El aparente diálogo inherente al género epistolar es puesto en duda por el discurso monológico de Jacopo. En Ultime lettere el Yo no es definido por el Tú, como en otras obras más propiamente epistolares. Foscolo se siente más cercano a Goethe que a Rousseau. A diferencia de la Nouvelle Héloiise, donde varios destinatarios reciben las cartas de numerosos remitentes, tanto en Werther como en Ultime lettere, el diálogo entre los amantes es sustituido por el monólogo del amante angustiado. La carta se convierte así en vehículo de afirmación personal más que de libre intercambio. Las reflexiones de Jacopo no parecen esperar una respuesta. La primera impresión que tenemos al leer la novela es la ausencia de intercambio epistolar. Pero, como hemos visto al nivel del contenido, la obra de Foscolo rehuye las simplificaciones. Como toda ausencia, el otro polo del esquema comunicativo epistolar se manifiesta en estado latente y surge, a veces, arrebatando el protagonismo al propio Jacopo. Esto ocurre en el caso de Lorenzo, destinatario principal de los desahogos emocionales del protagonista. Tras un detenido análisis de algunas de estas cartas, se deduce que son las cartas de Lorenzo, en realidad, las que desencadenan la compulsiva fiebre epistolar en Jacopo. Este último escribe a menudo en respuesta a los comentarios y consejos que anteriormente ha recibido de su amigo.

La labor de Lorenzo como editor, tiene aún mayores implicaciones en relación con el acto de leer. Lorenzo deviene prototipo del lector competente que no sólo se limita a consumir la obra literaria, sino que la organiza, le da forma y le confiere, en última instancia, su valor estético. Desde el punto de vista diegético, las cartas de Jacopo son simples confesiones que su amigo reúne en 
un todo consistente. Lorenzo, el destinatario, el lector y editor, es el artífice final de la obra literaria como tal. Transforma la materia prima en novela. En este punto se plantea la ambivalencia ideológica del discurso epistolar en Ultime lettere. El fragmentarismo de las cartas, invita a la colaboración del lector para llenar los "espacios de indeterminación," los "vacíos textuales" que va dejando tras de sí el propio texto. ${ }^{22}$ La novela pretende mostrarse, de esta forma, como espacio democrático para la interpretación, como estructura abierta a la recreación y, por tanto, a la reescritura. Como indica Verna: "Se davanti alle lacune dell'epistolario ortisiano Lorenzo non esita a sollecitare la collaborazione del lettore nella ricostruzione del testo, questo sarà un modo non solo per creare degli spazi autonomi d'interpretazione, ma anche per ridurre il grado di chiusura che la forma epistolare necessariamente comporta" (1989, p. 35). Pero esta aparente voluntad democrática se ve limitada al ser el propio Lorenzo quien emprende esta labor de reconstrucción. Sus comentarios en ocasiones sirven para vislumbrar situaciones que, de otra forma, permanecerían en la oscuridad para el lector. En otras ocasiones, sin embargo, su intrusismo en la narración (como el de Wilhelm en Werther) va más allá de la mera exposición de los hechos. En su notas "Al lettore" y en los fragmentos en tercera persona interpolados entre las últimas cartas, Lorenzo guía la actitud del lector hacia su propia interpretación de los acontecimientos. Detrás de su fría objetividad se esconde la manipulación que implica el mero hecho de clasificar unas cartas.

El texto, pues, invita a la participación del lector y la limita a un mismo tiempo. El espacio narrativo ha sido previamente invadido por el polivalente amigo-interlocutor-lector-editor, Lorenzo. A través de este último vislumbramos a un Jacopo atrapado en la red de sus propias contradicciones. El protagonista de Ultime lettere, un ser en el umbral de un cambio que refleja los cambios políticos de Italia en vísperas del Resorgimento. Burgués aristocrati-

22 El valor funcional de la indeterminación en la obra literaria ha sido objeto de estudio de la fenomenología hermenéutica -Ingarden (1973) e Iser (1978)- y la semiótica de Eco (1965). Para los dos primeros el significado de la obra no puede considerarse en esencia sino en acto. El estudio de la obra es indisociable de su efecto sobre el lector. El texto implica un potencial de significados que se actualizan en el acto de leer. De tales presupuestos se deduce la consideración de la lectura como un acto comunicativo en el que el intercambio de las partes (texto/lector) da lugar a la transformación de las mismas y al nacimiento del objeto estético. En cada una de las etapas del acto de leer, lo que está ausente, lo no dicho o lo negado ocupa un lugar central en el esquema comunicativo. Estos espacios de indeterminación no bloquean, sino que por el contrario estimulan la actividad representativa del lector a todos los niveles: estructural, cognitivo e ideológico. De modo semejante Eco comenta el valor de la ambiguiedad y la indeterminación dentro de la estética contemporánea: "...l'opera d'arte è un messaggio fondamentalmente ambiguo, una pluralità di significati che convivono in un solo significante" $(1965$, p. 6). 
zante, gira como una peonza en torno al núcleo magnético de una clase a la que pretendía destruir originalmente y que acaba por absorberlo. La visión pesimista de la naturaleza humana que Jacopo proclama no es sino la manifestación de su personalidad depresiva. ${ }^{23}$ Su incapacidad para materializar el más insignificante acto de rebelión política le lleva a escudarse en un nihilismo solipsista que tendrá su ultimación lógica en el suicidio.

\title{
Círculos viciosos: de la oralidad a la escritura, de la escritura al abismo
}

Wo fass ich dich, unendliche Natur?

Goethe

\begin{abstract}
Aber das Namenlose, Anonyme, wie rufst du's, Dichter, dennoch an? -Ich rühme.
\end{abstract}

Rilke

Claudio Guillén define la redacción de una carta como "ese tránsito humilde, primitivo, de la oralidad a la escritura" (1985, p. 168). En Ultime lettere el acto de escribir se convierte para Jacopo en la única posibilidad de afirmación ante la desesperanza amorosa y política. ${ }^{24}$ La paradoja de la obra de Foscolo es que este acto aparece encubierto bajo el espejismo de la oralidad. El epígrafe

23 La vida del propio Foscolo (poeta, soldado, activista político y profesor universitario) contrasta aparentemente con la inactividad de Jacopo en Ultime lettere. Recordemos, sin embargo, que lo descrito en la novela es tan sólo un corto periodo en la vida del protagonista y que las primeras páginas ya nos presentan a un Jacopo desilusionado y en espera de la muerte. El texto insinúa una vida anterior que podría ser similar a la del autor de la novela.

24 Como sugiere Matteo, "Politics and love are strategically paired arenas for Jacopo: the first is social, the second is personal. Failing in both. Jacopo fails in the two basic modes of human existence: the social and the individual. He does not find definition in society or in himself' (1985, p. 61). Al margen de lo cuestionable que es considerar el amor como algo meramente personal y lo político como social (el mencionado discurso de la Otredad y el narcisismo inherente a la actividad pública así lo desmienten), la cita de Matteo es pertinente en relación con la negatividad asociada a la figura de Jacopo. A su doble fracaso en el amor y la política se vendrá a sumar su fracaso como escritor, lo cual, como veremos, hace entrar en crisis al proceso literario propiamente dicho. 
que acompaña al título en las tres ediciones más importantes (Bolonia, 1798; Milán, 1802; y Zúrich, 1816) es una traducción latina de unos versos de Thomas Gray: "...naturae clamat ab ipso vox tumulo" ("Ev'n from the tomb the voice of Nature cries"). La voz de la naturaleza, pronto averiguamos, es la voz dominante en la novela, es decir, la voz de Jacopo. ${ }^{25}$ Si este recurso le permite trascendentalizar su discurso, conferirle dimensiones megalomaníacas, las palabras del epígrafe adquieren renovado sentido cuando el lector ha terminado la novela. Entonces comprendemos lo que en el fondo es un grito desesperado en favor de la creación artística como fuente de inmortalidad. El poeta, voz de la naturaleza, es capaz de trascender la muerte mediante el acto de la escritura. Pero esta capacidad queda en entredicho en el propio discurso de Jacopo. Las mismas contradicciones que frustran su discurso sentimental e ideológico se reproducen, con mayor fuerza, si cabe, en el plano de la creación. En la ya mencionada undécima carta ( 20 de noviembre), al intentar describir la belleza del paisaje y de la propia Teresa, Jacopo se enfrenta con las constricciones del lenguaje para expresar lo que es de por sí inefable:

Se potessi dipingerti la sua pronunzia, i suoi gesti, la melodia della sua voce, la sua celeste fisonomia, o trascrivere almeno tutte le sue parole senza cangiarne o traslocarne sillaba, certo che tu mi sapresti grado; diversamente, incresco perfino a me stesso. Che giova copiare imperfettamente inimitabile quadro, la cui fama soltando fa più impressione che la tua misera copia? (p. 147-148), ${ }^{26}$

25 La identificación y el sentimiento de ostracismo que el protagonista experimenta en relación con el mundo natural se manifiesta en numerosos pasajes (véanse por ejemplo las cartas del 20 de noviembre de 1797;19 de enero, 3-11-17 de abril, 13-15-25 de mayo, 2 de junio, 28 de julio, y 7 de septiembre de 1798; 19-20 de febrero, 5-14 de marzo de 1799). En todos ellos Jacopo proyecta su estado de ánimo en la naturaleza que se revela como madre (acogedora, benéfica, generadora de paz y quietud) o como matrigna (destructora y terrible). Esta ambivalencia del mundo natural que genera, a su vez, atracción y repulsión es característica de la estética del romanticismo. Las tesis de Argullol en relación con las artes plásticas pueden muy bien aplicarse al tratamiento del paisaje en Fóscolo: "el paisaje en la pintura romántica deviene un escenario en el que se confrontan naturaleza y hombre, y en el que éste advierta la dramática nostalgia que le invade al constatar su ostracismo con respecto a aquélla" (1983, p.10).

26 Esta misma situación había sido descrita por Goethe. En Werther el protagonista se lamenta de ser incapaz de expresar mediante el lenguaje la belleza de Lotte: "Cependant, Werther, qui autrefois dessinait abondamment et bien, ne peut faire le portrait de Charlonte...'J'ai perdu... la force sacréc, vivifiante, avec quoi je créais autour de moi des mondes"' (Barthes 1975, p. 113). 
La escritura como problema pasa así a ocupar el primer plano de la narración junto a los otros motivos apuntados (la imposibilidad de su amor apasionado, la desintegración de Italia y el anhelo de muerte). En la propia textura de las cartas se reproduce la personalidad esquizoide que veíamos en el discurso político del protagonista. Junto al tono general de las cartas que pretende revelarse como espontáneo, casi oral (aunque este efecto de oralidad no es más que un recurso literario), se entrecruzan pasajes de una extraña artificiosidad. Estos últimos son especialmente frecuentes en las descripciones del mundo natural:

S'apriva appena il più bel giorno d'autunno. Parea che la notte seguita dalle tenebre e dalle stelle fuggisse dal sole, che uscìa nel suo immenso splendore dalle nubi d'oriente, quasi dominatore dell'universo; e l'universo sorridea. Le nuvole dorate e dipinte a mille colori salivano su la volta del cielo che tutto sereno mostrava quasi di schiudersi per diffondere su i mortali le cure della divinità. lo salutava a ogni passo la famiglia de' fiori e dell'erbe che a poco a poco alzavano il capo chinato dalla brina. Gli alberi susurrando soavemente, faceano tremolar contro la luce le gocce transparenti della rugiada; mentre i venti dell'aurora rasciugavano il soverchio umore alle piante. Avresti udito una solenne armonia spandersi confusamente fra le selve, gli augelli, gli armenti, fiumi, e le fatiche degli uomini; e intanto spirava l'aria profumata dalle esalazioni che la terra esultante di piacere mandava dalle valli e dai monti al Sole, minostro maggiore della Natura (p. 146-147).

Abundan en este fragmento las figuras conceptistas heredadas del barro-
co y del neoclasicismo.

27 Matteo comenta el acusado contraste entre la rigidez de este pasaje, que atribuye a la estética barroca, y la aparente libertad del resto de la novela. Para Matteo, el fragmento citado es representativo de la ambivalencia característica del discurso de Jacopo: por un lado, contribuye a establecer la autoridad de Jacopo como narrador, por el otro, busca ganarse la simpatía del lector mostrando la capacidad del personaje para apreciar la belleza del mundo natural. El estilo de la narración se revela a un mismo tiempo como alienante y seductor, aunque en el ejemplo en cuestión domina la primera de talas características. Matteo analiza en estos términos el mecanismo retórico y el convencionalismo de la mencionada descripción paisajística: "The passage is constructed by a remarkable series of conceits, the predominance of which makes it possible to label the passage as 'Baroque'. From the first metaphor of the night and the stars fleeing from the advancing sun; through 
posible salida a su dilema personal -la afirmación de su Yo mediante el acto de la escritura en toda su artificiosidad, el intento se revela fútil. No es la voz de Jacopo la que habla, sino la de la tradición. Una tradición que dicta las normas que precisamente desafiaba el movimiento romántico. ${ }^{28}$ En el resto de la novela la voz narrativa se empeñará en recalcar la inefabilidad de todo lo bello y la impotencia del artista para plasmar tal belleza sobre el papel o el lienzo. ${ }^{29}$ Esta permanente ambivalencia entre el deseo compulsivo de escribir, de trascender, por tanto, la simple oralidad, y la tendencia a privilegiar lo natural como "esencia", la palabra hablada como "verdadera" (frente a la supuesta falsificación de la literatura), revela el impulso paradójico que guía el pensamiento de Jacopo. En términos deconstructivistas podíamos definirlo como la sustitución de un centro (la tradición literaria) por una nueva jerarquía (la creación de un lenguaje de la espontaneidad) que sustituye a la anterior y se manifiesta, en última instancia, tan inoperante como ésta. ${ }^{30}$

the personification of the similing universe, and 'la famiglia de' fiori e dell'erbe che a poco a poco alzavano il capo chinato dala brina'..., and the whispering trees; to the final personification and antonomasia of the sun as Nature's greatest 'minister', the passage is a continuous chain of rhetorical tropes" (1985, p. 86).

28 La estética de Werther es más coherente en este sentido. La prosa de Goethe se libera de las constricciones del clasicismo pero, además, hace explícita esa liberación mediante los comentarios airados del protagonista: "It is possible to say a good deal in favor of rules, about as much as can be said in praise of bourgeois society. The person who takes his direction from rules alone will never produce anything in bad taste, in the same way as the person who allows himself to be sahped by rules of social convention can never become an intolerable neighbor or a conspicuous villain; on the other hand, any rule is likely to destroy both the true feeling of Nature and its true expression, whatever people may say to the contrary" (1971, p. 14).

29 En su carta del 14 de mayo de 1798, Jacopo expresa claramente la incapacidad del arte en todas sus modalidades para reflejar el esplendor de la naturaleza: "Ma...se anche fossi pittore? ho veduto ne' pittori e ne' poeti la bella e talvolta anche la schietta natura, ma la natura somma, immensa, inimitabile non l'ho veduta dipinta mai. Omero, Dante, e Shakespeare, i tre maestri di tutti gl'ingegni sovrumani, hanno investito la mia imaginazione ed infiammato il mio cuore: ho bagnato di caldissime lagrime $\mathrm{i}$ loro versi; e ho adorato le loro ombre divine come se le vedessi assise su le volte eccelse che sovrastano l'universo a dominare l'etemità. Pure gli originali che mi vedo davanti mi riempiono tutte le potenze dell' anima, e non oserei, Lorenzo... non oserei, se anche si trasfondesse in me Michelangelo, tirarne le prime linee" (p. 195-196). Teniendo en cuenta la admiración que Jacopo dice profesar por todos estos clásicos que cita no ya sólo en este pasaje sino a lo largo de toda la novela, el fragmento en cuestión debe interpretarse como un acto de rendición, una aceptación de la futilidad del acto de escribir y, por lo tanto, como un indicio más del discurso suicida del protagonista.

30 Siguiendo algunos de los conceptos expuestos por Derrida (1967a), podríamos interpretar la búsqueda de Jacopo como una metáfora de esa otra búsqueda que ha dominado el pensamiento occidental desde sus origenes: la mencionada búsqueda de un centro que garantice el 
Por otra parte, los clisés y las imágenes características de la tradición producen un contraste estridente con la naturalidad $y$, a menudo, el descuido de la voz narrativa en la mayor parte de las cartas. Estos dos estilos reclaman, a su vez, dos tipos diferentes de audiencia: el lector informado y competente, capaz de captar el significado de las imágenes a la luz de la tradición literaria en la que se inscriben y un tipo de lector ávido de rupturas, que busca en el desenfado y la libertad estilística del narrador una salida a las trabas formales del neoclasicismo.

De nuevo, la tensión narrativa surge de una oposición entre tendencias de carácter contradictorio. La búsqueda de un nuevo lenguaje y de una nueva audiencia burguesa se mantiene bajo la estrecha vigilancia de la tradición aristocratizante. El narrador desea huir del centro simbólico de dicha tradición, pero es incapaz de sobrepasar su marco. Jacopo queda atrapado en los márgenes. Esta situación es dramatizada por el propio texto. En los momentos finales de la novela Jacopo no tiene fuerzas para proseguir su labor epistolar. Su única actividad relacionada con el acto de escribir consiste en anotar pensamientos al margen de las obras de Plutarco, Marco Aurelio y Tácito. Todo su afán queda reducido a una simple nota a pie de página de los clásicos. Sus últimas palabras, de hecho, son citas de Alfieri y Dante (dos nuevos jalones - renacimiento y neoclasicismo - dentro de la genealogía clásica italiana). En uno de sus últimos encuentros con el Signor T*** Jacopo se vale de una pasaje de Alfieri para comunicar su intención de suicidarse:

Non diedi a voi per anco

Del mio coraggio prova: ei pur fia pari

Al dolor mio (p. 270).

ser como presencia. Términos tales como ser, esencia, sustancia, verdad, forma, principio, fin, propósito, conciencia, hombre, Dios, etc., actúan como principios centralizadores. Derrida descarta la posibilidad de pensar fuera de estos términos. Lo único que podemos hacer es evitar que uno de los polos del sistema se convierta en un nuevo centro que garantice esta presencia ilusoria. El error de Jacopo, su nuevo suicidio discursivo, se produce al no ser capaz de articular las ambivalencias de su pensamiento, privilegiando siempre uno de los dos términos de la oposición, esto es, pensando siempre en términos absolutos. Tras sucesivos intentos por hacer del amor y la lucha política ese vehículo de afirmación, Jacopo experimenta la misma frustración en el acto de escribir. Pero su desconfianza en el valor de la escritura (algo característico del pensamiento "logocéntrico"), le lleva a renegar de su única posibilidad de salvación. 
JUAN-NAVARRO, S. Las epístolas del abismo...

De modo similar, cuando Jacopo poco antes de morir visita a su madre en Venecia, descubre una retrato suyo pintado por Teresa. El cuadro muestra un verso de Dante "Libertà va cercando ch'è sì cara" (p. 464). A través del comentario de Lorenzo sabemos que es el padre de Teresa quien le había sugerido la inscripción, revelándose una vez más como portavoz de la tradición. El verso es completado por Lorenzo, que asume así el mismo papel que il Signor $\mathrm{T}^{* * *}$ : "Come sa chi per lei vita rifiuta" (p. 464). ${ }^{31}$ La escena no sólo sirve para justificar la muerte de Jacopo como una especie de inmolación patriótica. Adivinamos desde los comienzos de la novela un progreso que bien podríamos calificar de regresión cíclica, de círculo vicioso: de los intentos de reforma, Jacopo pasa a aceptar el establishment, pero las contradicciones entre estos dos tipos de discurso político le llevan a abandonar el acto de escribir. ${ }^{32}$ Su discurso último consiste en una oralidad oximorónica, ya que no se revela como espontánea (rasgo asociado al habla), sino artificiosa (característica de la escritura): Jacopo habla la literatura escrita. El impulso que le movía a intentar dar expresión a un lenguaje literario que fuera al mismo tiempo oral y escrito, sin desprenderse del lastre de la tradición acaba por emplazarlo en un nuevo callejón sin salida, donde Jacopo es nuevamente aniquilado.

La forma en que Jacopo lleva a cabo su suicidio contiene un alto potencial simbólico. En los instantes finales podemos ver reunidos muchos de los temas que hemos venido anotando. Al igual que en Werther, el escenario de la muerte del héroe se corresponde con lo que Derrida (1967b) llama "la scène de l'écriture." ${ }^{33}$ Hasta el último momento Jacopo intenta escribir varias cartas que quedan reducidas a simples borradores, fragmentos llenos de tachaduras y frases inarticuladas. Junto a su escritorio se clava una daga en el pecho y, aunque no consigue atravesar el corazón, muere desangrado en los brazos del Signor T***. En el momento en que el puñal se hunde en su pecho pronuncia "un lungo gemito." La supremacía del sentimiento simbolizada en el corazón ("tutto dipende dal cuore") es víctima de la agresión final de Jacopo, aunque no es

31 Los versos de Dante aparecen como epigrafe en la primera página de la edición londinense de 1817 , lo que, además de dar al texto una nueva nota ominosa, confiere a la psicología del personaje principal un carácter recurrente.

32 El rechazo de la escritura se manifiesta de forma violenta mediante la quema de cartas y escritos, especialmente al final de la obra, cuando la frustración de Jacopo ante los límites del lenguaje se hace más obsesiva (p. 141, 267, 276).

33 En la página final de la novela de Goethe, Wilhelm, en su meticulosa descripción, no escamotea los detalles macabros: "From the blood on the back of the armchair they concluded that he dad committed the act while sitting at his writing desk. He had then slid down and rolled around the chair in convulsions $(1971$, p. 166). 
directamente destruida. En un extraño gesto final de abrazo y de rechazo del padre de Teresa, Jacopo manifiesta de nuevo la ambigua mezcla de atracción y repulsión que siente por este personaje. ${ }^{34} \mathrm{El}$ último mensaje no es, lógicamente una carta, sino un gemido, una vuelta no ya a la simple oralidad, sino a aquella que precede a la articulación lingüística del pensamiento, una regresión al primer sonido emitido al nacer. ${ }^{35}$ Con este gemido, Jacopo, la voz de la naturaleza, vuelve a ella, para disolverse en el abismo.

\section{RESUMEN}

En su obra más conocida (Ultime lettere di Jacopo Ortis) el autor italiano del siglo XVIII Ugo Foscolo reúne y explora los motivos y técnicas tradicionalmente asociados al género epistolar. Esta reflexión se materializa en tres niveles discursivos: amoroso (búsqueda de la plenitud personal a través de un objetode deseo), político (lucha por la unidad e identidad nacionales) y literario (creación de una nueva forma de expresión y de una nueva audiencia). En cada uno de estos tres niveles las contradicciones del protagonista, Jacopo Ortis, le sitúan en un callejón sin salida del que sólo puede escapar mediante su autodestrucción.

La intención del presente ensayo es estudiar cada uno de estos niveles en relación con la estructura epistolar de la novela de Foscolo. Aunque tales niveles discursivos (amoroso, político y literario) tienden a ser considerados por separado, en mi ensayo planteo una correlación íntima de los tres a la luz de las teorias de Roland Barthes (Fragments d'un discours amoureaux), Mikhail Bakhtin (Problems in Dostoev'sky's Poetics) y Jacques Derrida (De la grammatologie y L'écrilure et la différence).

Mi análisis contempla la fragmentación del material narrativo y la dispersión de sus voces y destinatarios como reflejo de la escisión espiritual característica del hombre romántico y de la desintegración política de Italia a comienzos del siglo XIX. Por otro lado, considero que la tensión resultante del enfrentamiento entre postulados estéticos

34 "ll signore $\mathrm{T}^{* * *}$ gli sollevava lievemente dalla ferita la camicia, che tutta inzuppata di sangue gli si era attaccata sul petto; Jacopo si risenti; ed alzò il viso verso di lui c guardandolo con gli occhi nuotanti nella morte stese un braccio per impedirlo, e tentava con l'altro di stringergli la mano...ma ricascando con la testa sui guanciali, levò gli occhi al cielo e spirò" (p. 289).

35 El gemido final de Jacopo manifiesta la regresión del lenguaje a ese estado primordial que Lacan llama Lalangue y que Jacques Alain-Miller interpreta como "a pregrammatical and prewritten level of language" (1990). Lalangue, como señala Lacan, trabaja al nivel del sonido. Es esa especie de masa verbal informe sobre la que está construida la gramática: "Lalangue, as one word (wi or with the article soldered onto the substantive, instead of la langue): general equivocation, universal babble, or 'Babelonian'" (Lacan 199, p. 6). 
(neoclasicismo y romanticismo) y conceptos excluyentes (artificiosidad y espontaneidad, escritura y oralidad) tiende en última instancia, a problematizar el acto mismo de escribir $\mathrm{y}$, por lo tanto, la base misma del género epistolar.

Palabras-clave: Ugo Foscolo, Ultime lettere di Jacopo Ortis, novela epistolar, fragmentación y dialogismo.

\section{RESUMO}

Em sua obra mais conhecida (Ultime lettere di Jacopo Ortis), o autor italiano do século XVIII, Ugo Foscolo, reúne e explora os motivos e técnicas tradicionalmente associados ao gênero epistolar. Esta reflexão se materializa em três níveis discursivos: amoroso (busca da plenitude pessoal através de um objeto de desejo), político (luta pela unidade e identidade nacionais) e literário (criação de uma nova forma de expressão e de uma nova audiência). Em cada um desses três níveis as contradiçōes do protagonista, Jacopo Ortis, o situam em um beco sem saída de que só pode escapar mediante sua autodestruição.

A intenção do presente ensaio é estudar cada um desses três níveis em relação à estrutura epistolar do romance de Foscolo. Ainda que tais níveis discursivos (amoroso, político e literário) tendam a ser considerados em separado, em meu ensaio estabeleço uma correlação intima dos três à luz das teorias de Roland Barthes (Fragmentos de um discurso amoroso), Mikhail Bakhtin (Problemas da poética de Dostoiévski) e Jacques Derrida (Gramatologia e A escritura e a diferença).

Minha análise contempla a fragmentação do material narrativo e a dispersão de suas vozes e destinatários como reflexo da cisão espiritual do homem romântico e da desintegração política da Itália nos primórdios do século XIX. Por outro lado, considero que a tensão resultante do enfrentamento entre postulados estéticos (neo-classicismo e romantismo) e conceitos excludentes (artificiosidade e espontaneidade, escrita e oralidade) tende, em última instância, a problematizar o ato de escrever e, portanto, a base do gênero epistolar.

Palavras-chave: Ugo Foscolo, Ultime lettere di Jacopo Ortis, romance epistolar, fragmentação e dialogismo. 


\section{BIBLIOGRAFÍA}

ALTMAN, Janet Gurkin. Epistolarity: approaches to a form. Columbus: Ohio University Press, 1982.

ARGULLOL, Rafael. El héroe y el único: el espíritu trágico del Romanticismo. Madrid: Taurus, 1982.

La atracción del abismo: un itinerario por el paisaje romántico. Barcelona: Bruguera, 1983.

BAKHTIN, Mikhail. Problems of Dostoevsky's poetics. Trad. de Caryl Emerson. Minneapolis: University of Minnesota Press, 1984.

BARTHES, Roland. Fragments d'un discours amoureux. Paris: Éditions du Seuil, 1977.

BERENGO, M. (Ed.). Lezioni sul Foscolo. Firenze: La Nuova Italia Editrice, 1981.

BINNI, Walter. Ugo Foscolo: storia e poesia. Torino: Giulio Einaudi, 1982.

CAMBON, Glauco. Ugo Foscolo: poet of exile. Princeton: Princeton University Press, 1980.

CARPANETTO, Dino; RICUPERATI, Gino. Italy in the age of reason: 1685-1789. London and New York: Longman, 1987.

DAPELO, C. Werther e Ortis. Lettere italiane 5, 1953. p. 176-186.

DERRIDA, Jacques. De la grammatologie. Paris: Minuit, 1967a.

L'écriture et la différence. Paris: Seuil, $1967 \mathrm{~b}$.

ECO, Umberto. Opera aperta: forma e indeterminazione nelle poetiche contemporanee. Milano: Bompiani, 1967.

FOSCOLO, Ugo. Edizione Nazionale delle Opere di Ugo Foscolo. Ultime lettere di Jacopo Ortis. Giovanni Gambarin (Ed.). Firenze: Felice Le Monnier, 1970. v. 4.

FRATTINI, Alberto. Il neoclassicismo e Ugo Foscolo. Rocca San Casciano: Cappelli, 1965.

GOETHE, Johann Wolfgang von. The sorrows of young Werther and novella. Trad. de Elizabeth Mayer e Louise Bogan. New York: Random House, 1971.

Las desventuras del joven Werther. Trad. de Manuel José González. Madrid: Cátedra, 1989.

GUILLÉN, Claudio. Entre lo uno y lo diverso: introducción a la literatura comparada. Barcelona: Editorial Crítica, 1985.

. Teorias de la historia literaria: ensayos de teoría. Madrid: Espasa-Calpe, 1989.

GRAFF, A. Su le ultime lettere del Foscolo e il Werther del Goethe. Nuova Antologia $57,1895$.

HEARDER, Harry. Italy in the age of the risorgimento 1790-1870. London and New York: Longman, 1987.

INGARDEN, Roman. The literary work of art: an investigation on to the borderlines of ontology, logic and the theory of literature. Trad. de George G. Grabowicz Evanston. Illinois: Northwestem University Press, 1973.

ISER, Wolfgang. The act of reading: a theory of aesthetic response. Baltimore: John Hopkins University Press, 1978. 
JUAN-NAVARRO, S. Las epístolas del abismo...

LACAN, Jaques. Television: a challange to psychoanalytic establishment. Joan Copejec (Ed.). Trad. de Denil Hollier et al. New York: Norton, 1990.

MANACORDA, Giuseppe. Materialismo e masochismo: il Werther, Foscolo e Leopardi. Firenze: La Nuova Italia, 1973.

MARPILLERO, G. Werther, Ortis e il Leopardi. Giornale storico della letteratura italiana n. 36 (1900). p. 350-78.

MASSANO, Riccardo. Goethe e Foscolo, Werther e Ortis. In: Problemi di lingua e letteratura italiana del Settecento. Associazione internazionale per gli studi di lingua e letteratura italiana. Wiesbaden: Franz Steiner Verlag, 1965. p. 231-238.

MATTEO, Sante. Textual exile: the reader in Steme and Foscolo. New York: Peter Lang, 1985.

MILLER, Jacques-Allan. A reading of some details of Lacan's television. A challange to psychoanalytic establishment in dialogue with the audience. The Lacan Conference 1990. Barnard College. New York, 14-15 April 1990.

NICOLETTI, Giuseppe. Il "metodo" dell" "Ortis" e altri studi foscoliani. Firenze: La Nuova Italia Editrice, 1978.

PUGLIESE, Guido (Ed.). Perspectives on nineteenth-century italian novels. Ottawa: Doverhouse Ed., 1989.

RADCLIFF-UMSTEAD, Douglas (Ed.). Ugo Foscolo's ultime lettere di Jacopo Ortis: a translation. Chapel Hill: The University of North Carolina Press, 1970a. Ugo Foscolo. New York: Twayne, 1970b.

RIMMON-KENAN, Shlomith. Narrative fiction: contemporary poetics. London and New York, 1983.

SELDEN, Raman. A reader's guide to contemporary literary theory. Brighton: The Harvest Press, 1986.

TODOROV, Tzvetan. Mikhail Bakhtin: the dialogical principle. Trad. de Wlad Godzich. Minneapolis: University of Minnesota Press, 1984.

VARESE, Claudio. Foscolo: sternismo, tempo e persona. Ravenna: Longo Editore, 1982.

ZUMBINI, B. Werther e Jacopo Ortis. In: Studi di letteratura comparata. Bologna: Zanichelli, 1930. 